\title{
Formant Transition of Nasal and Liquid in the External Auditory Canal
}

\author{
SeungDeok $\mathrm{Heo}^{\mathrm{a}}$, DoYun Kim ${ }^{\mathrm{b}}$ \\ ${ }^{a}$ Department of Speech-Language Pathology, College of Rehabilitation Science, Daegu University, Gyeongsan, Korea \\ ${ }^{b}$ Department of Rehabilitation Science, Graduate School of Daegu University, Gyeongsan, Korea
}

\author{
Correspondence: Seung-Deok Heo, PhD \\ Department of Speech-Language Pathology, \\ College of Rehabilitation Science, Daegu \\ University, 201 Daegudae-ro, Jillyang-eup, \\ Gyeongsan 38453, Korea \\ Tel: $+82-53-850-4326$ \\ Fax: $+82-53-850-4329$ \\ E-mail: audiolog@daegu.ac.kr
}

Received: February 7, 2018

Revised: July 22, 2018

Accepted: August 14, 2018

This research was supported by the Daegu University Research Grant 2017.
Objectives: While speech sounds can be heard and understood through the external ear (EE), the EE transmits the sound through the air as a medium. Consequently, acoustic characteristics of speech sounds differ depending on the structure of the EE or the physical characteristics of the medium. This study aims to investigate how the characteristics of the EE's acoustic transmission affect the formant transition (FT) of nasals and liquids. Methods: Sixteen healthy men and women who had no problems in their auditory or articulation system participated in this study. One participant acted as the speaker, and the remaining 15 participants were listeners. In terms of the voice, monosyllabic words which combined the nasal / $\mathrm{n} /$ and liquid /// with the vowel /a/ were used. When recording, a high-performance microphone was used, and mounted on the upper pinna and the external auditory canal respectively. The recorded voice was calibrated with MATLAB, and the FT was analyzed with Praat. The differences between the two voices were analyzed with a two-way ANOVA. Results: In the sound field, the FT was elevated for both nasals and liquids with the exception of $\mathrm{F} 4$ which showed an increase following a decrease. In the EAC, regarding the formant transfer, only F1 and F2 exhibited an elevation, while F3 decreased, and F4 was maintained in the case of nasals. In the case of liquids, it was observed that although F1 and F4 were elevated, F4 was nearly horizontal, F2 showed a decrease, and F3 was maintained. Conclusion: The formant transition of the external auditory canal contributes to improving the discriminative qualities of speech by broadening the formant spacing of nasal F3, F4, and liquid F2, F3, and F4.

Keywords: Formant, Formant transition, Nasal, Liquid, External auditory canal, Real ear
포먼트 주파수는 음향학적 특징 중 하나로 구강 및 비강 모양과 구강 내에서 혀의 높낮이 등 조음 방법에 의해 결정이 되며, 단모음 의 특성을 기술한다. 그러나 모음의 포먼트 주파수는 시간에 따라 변화하며, 이러한 변화를 포먼트 전이(formant transition)라 한다. 포먼트 전이는 성도 모양이 달라지면서 생기는 포먼트의 이동으로 조음 위치에 대한 정보를 담고 있다(Johnson, 2003). 이들 포먼트 주파수와 포먼트 전이는 다양한 화자나 말소리 환경에서도 모음을 인지하는데 중요한 음향학적 정보를 제공한다.

자음은 음향학적 특성에 따라 공명음과 저해음으로 구분하고 유성 자음은 다시 비음과 유음(liquid)으로 구분한다. 우리말은 음 운론적 차이로 의미가 달라지지 않아서/ㄴ/, /ㄹ/, /ㅁ/, / ㅇ만을 유
성 자음으로 보기도 한다. 이 중 /ㄴ/과 /리은 비음과 유음으로 분 류하지만 유성 자음이면서 치경음(alveolar)으로 동일하다. 비음은 선행이나 후행 모음의 포먼트 전이 구간을 통해 조음 위치를 쉽게 판단할 수 있다. 유음은 'ㄹ' 계통으로 실현되는 소리를 말하는데, 유음에는 달, 별, 말 등과 같이 기류가 혀의 몸통(tongue body) 양 옆으로 빠져나오는 소리로 포먼트가 있는 설측음(lateral)과 나라, 다리, 소리 등과 같이 잇몸을 혀끝(tongue apex)으로 가볍게 부딪 친 후 기류가 구강 중앙으로 빠져나오는 소리로 포먼트가 없는 탄 설음(flap, tap)으로 구분한다.

비음은 반공명 주파수를 갖는 공명음이지만 비강을 통하기 때 문에 성도가 길어져서 공명주파수가 모음에 비하여 낮고, 에너지 
도 약하다. 유음은 비강을 통하지 않기 때문에 에너지 감폭(damping)이 적으나 비음처럼 고주파수 대역의 음향에너지가 낮다. 성대 가 폐쇄되는 시간 비율은 성대 접촉률(closed quotient, $\mathrm{CQ}$ )로 표현 할 수 있고, 전기성문도(electroglottography)로 측정할 수 있다. CQ 는 모음이나 공명자음에서 측정할 수 있는데 모음에서는/우/가 높 고, 공명 자음에서는 비음이 높다(Choi, Nam, Lim, Lim, \& Choi, 2007).

모음이나 공명자음의 음향학적 특성은 성도를 지나온 뒤 방해 가 없는 음장(sound field, SF)에서 녹음한 음성으로 분석한 결과이 다. 그러나 소리는 청자가 청각기관을 통해 청취하며, 청각기관은 소리에너지 형태를 다양하게 변환한다. 소리에너지 전달이 음장에 서와 마찬가지로 공기를 매질로 하는 부분은 외이(external ear)이 며, 신체에서 외이의 위치와 구조상 특징으로 음향 특성이 달라질 수 있다.

청각기관에서 외이는 이개(pinna), 이개강(concha cavity), 외이 도(external auditory canal, EAC) 등으로 구성되는데, 직경이 $1 \mathrm{~cm}$ 이내로 작으며 'S' 모양의 굴곡이 있고, 한 쪽이 고막으로 막힌 맹관 인 구조상 특징으로 공명을 일으킨다. 외이에서의 공명주파수는 이개에서 약 $4 \mathrm{kHz}$ 범위, 이개강에서 5-6 kHz 범위, 외이도에서 2.7 $\mathrm{kHz}$ 범위이며, 공명 이득은 입사각에 따라 다소 차이가 있지만 최 대 $20 \mathrm{~dB}$ 미만이다(Heo, Lee, Jeon, \& Kim, 2010; Heo, 2012). 이러 한 음향특성 변화는 소리가 한 쪽에서 들려오는 경우 같은 방향의 소리를 증강시켜 방향을 구별하는 데 중요한 단서(Heo, Choi, \& Kang, 2006)를 제공하기도 하고, 외이 공명에 의한 매질 전달특성 등이 말소리 음향특성에 영향(Heo \& Kang, 2017; Heo, Kang \& $\mathrm{Ko}, 2017)$ 을 주는 것으로 확인되었다.

포먼트 전이는 시간에 따라 변하는 단모음의 특성과 조음 기관 변화에 따른 조음 정보가 담겨 있는데, 증폭장치 사용으로 생기는 공명 손실에 의한 영향이나 증폭장치 사용자들이 흔히 겪는 과도 비성이나 모음 오류 확인에 도움을 받을 수 있을 것으로 추정된다. 아울러 말소리의 방향성 판단과 관련한 단서를 얻을 수 있을 것으 로도 기대된다. 그러나 이와 관련한 포먼트 전이 연구는 시행되지 않았다.

이 연구는 유성 자음이면서 비음과 유음으로 분류되지만 치경 음으로 동일한 / ㄴ/과 /리을 혀가 안정되고 구강 내 간섭이 적은 모 음//와 연결하여 발성한 후, 외이도 내부에서 녹음한 단음절 낱 말의 포먼트 주파수 전이가 이개 상부 음성과 비교하여 어떻게 달 라지는지 살펴보는 데 목적이 있다.

\section{연구방법}

\section{연구대상}

참여자는 모두 신체적 정신적으로 건강한 16 명이었고, 이들은 화자와 청자로 나누었다.

화자는 청각기관과 특히, 조음 기관의 구조와 기능이 정상이며, 언어병리학을 전공한 22 세의 남자 대학생 1 명이었다. 이 연구는 외 이 공명에 의한 영향을 살펴보기 위한 것으로 단일 화자의 음성을 사용하였고, 화자는 성별보다 좋은 발화명료도만을 고려하였다.

청자는 조음 기관과 특히, 외이 기형이 없고 고막과 중이 기능이 정상인 평균 26 세의 15 명(남자 3 명, 여자 12 명)이었다. 청자의 고막 과 중이의 상태는 공명 등으로 결과에 영향을 줄 수 있어서 객관적 평가도구인 고막운동성계측(tympanometry, GSI 33 middle ear analyzer; Grason-Stadler Inc., Eden Prairie, MN, USA)으로 확인 하였다. 이들의 고막운동도(tympanogram)는 외이도 용적(ear canal volume), 정적 탄성(static compliance), 중이강 압력(middle ear pressure) 등이 모두 미국언어청각협회(American Speech-Language Hearing Association) 정상 기준에 해당하는 A형으로 관찰 되었다. A형 고막운동도는 고막 천공이 없고, 이소골과 이관의 기 능이 정상 소견임을 의미하며, 제한적이지만 남녀 차이가 관찰되지 않아 청자 성별은 구분하지 않았다.

이들의 청력은 스마트폰 순음청각선별 애플리케이션(pure tone hearing screening, Project team for audiology study in Daegu University, Gyeongsan, Korea; Heo, Park, \& Song, 2017)으로 1,000, $2,000,3,000,4,000 \mathrm{~Hz}$ 를 방음 실에서 검사하였고, 가청역치는 대상 자 모두 $15 \mathrm{~dB} \mathrm{HL}$ 이내로 정상 범위에서 관찰되었다.

연구 참여자들은 연구의 목적과 방법에 대해 충분히 이해하였고, 연구목적에 따른 결과의 활용에 동의하였다.

\section{연구방법}

화자의 발성과 청자 외이도에서 녹음, 청각선별 등 모든 과정은 방음실(IAC 1204A, Industrial Acoustic Company, North Aurora, $\mathrm{IL}, \mathrm{USA}$ ) 내부에서 진행하였다.

녹음용 마이크는 성능이 같은 두 개의 고성능 콘덴서 마이크를 이용하여 자체 제작하였다. 제작한 마이크는 일회용 주사기에 넣고 몰딩하였다. 두 개의 마이크 중 하나는 외이도 내부의 음성을 녹음 할 수 있도록 길이를 $0.5 \mathrm{~cm}$ 로 평면 절단한 의료용 18 게이지 주사 바늘(18G $\times 1 \frac{112}{2}$, Shinchang Medical, Gumi, Korea)과 직경 0.6 $\mathrm{mm}$, 길이 $75 \mathrm{~mm}$ 인 별도의 실이 계측용 실리콘 탐침관을 주사기 끝에 달았다(외이도 마이크, $\mathrm{EAC} \mathrm{mic}$ ). 나머지 마이크는 주사 바 

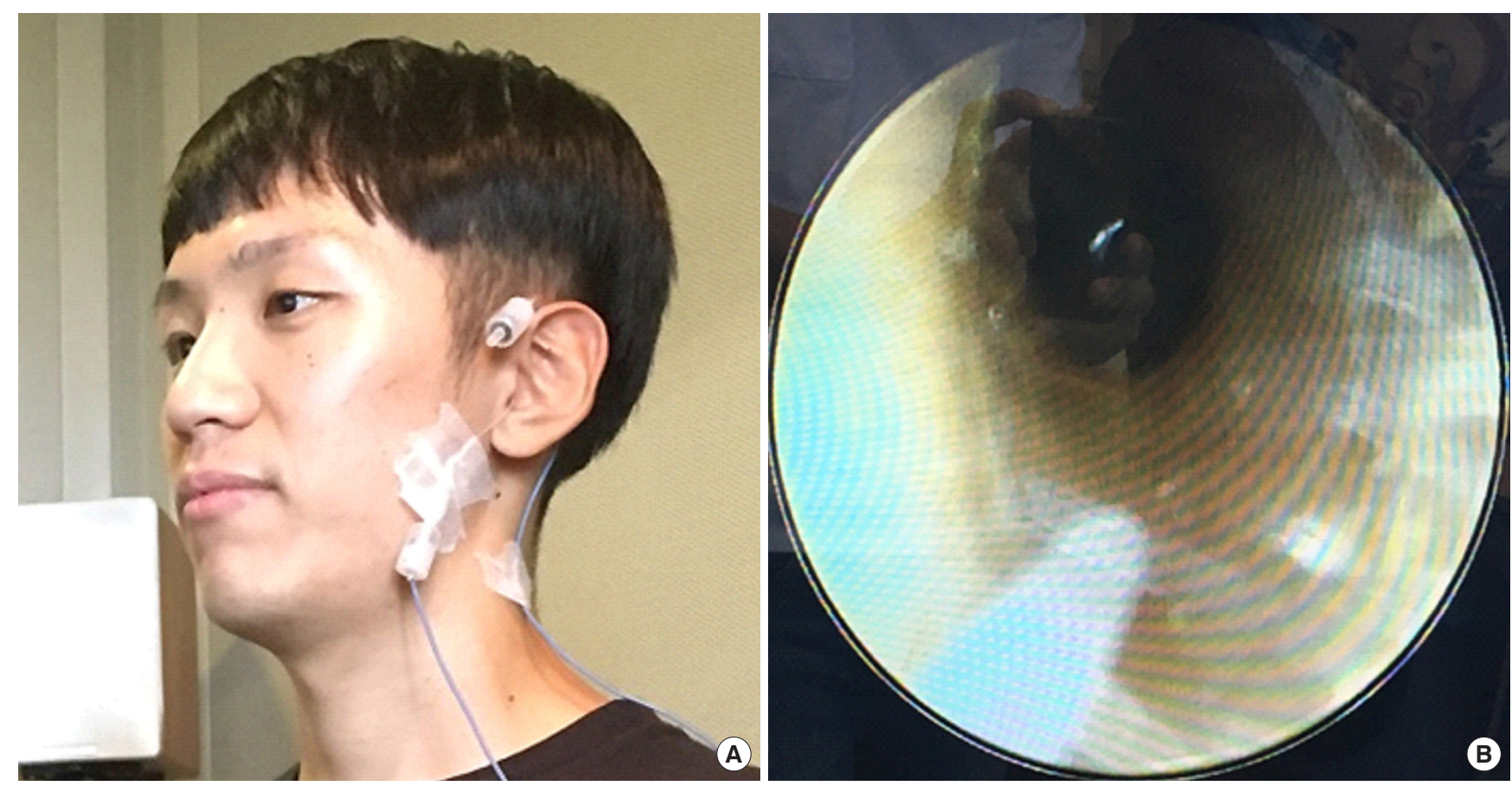

Figure 1. Sound field microphone above the pinna, external auditory canal microphone with probe attached (A) and probe tube inserted into the external auditory canal (B).

늘이나 탐침관을 달지 않고 사용하였다(음장 마이크, SF mic) (Figure 1).

$\mathrm{EAC} \mathrm{mic}$ 는 내시경 장치(XVS3, 참메드, 군포, 한국)로 외이도 내 부를 감시하면서 탐침관 끝을 외이도 안쪽 고막 $1 \mathrm{~cm}$ 가까이까지 삽입한 후, 노출된 탐침관을 이수(lobule)에 대고 접착테이프로 고 정하였다. SF mic는 마이크 입력단이 전방을 향하게 한 후, 주사기 를 이개 상부에 대고 접착테이프로 고정하였다. 두 마이크에 연결된 전선은 클립을 이용하여 참여자상의에 단단히 고정하였다(Figure 1). 발성은 유성 자음/ㄴㄱㄱㅘ/리를 모음///와 연결한/나/와/라/를 각각 5 초 이상 강도를 일정하게 지속할 수 있도록 음성분석장비 Computerized Speech Lab. (CSL Model 4500, KayPentax, Montvale, NJ, USA)와 소프트웨어(Multi-Dimensional Voice Program Model 5105 version 3.3.0.)의 음량지시계(volume unit meter)를 관 찰하면서 충분히 연습하게 하였다. 연습을 마친 후, 안정적으로 발 성한 음성을 CSL에 연결된 PC를 이용하여 녹음하였다.

녹음한 화자의 음성은 개인용 컴퓨터(DBP400-PC313S, 삼성전자, 수원, 한국)에 설치한 Audition CS6 (Adobe, San Jose, CA, USA)와 스피커(BR-2280 Stick; Britz, Paju, Korea)를 이용하여 75 dB SPL 강도로 재생하였다. 이때 스피커는 청자의 좌측 $45^{\circ}$ 전방 $50 \mathrm{~cm}$ 지 점에 배치하였다. 재생한 음성은 두 개의 SF mic와 EAC mic로 동 시에 받아 2채널 증폭기(Scarlett 6i6)로 증폭하고, Audition CS6에
서 $44,100 \mathrm{~Hz}$ 비율로 녹음하여 별도의 개인용 컴퓨터(DBP400PC313S; Samsung, Suwon, Korea)에 저장하였다. 개인용 컴퓨터에 저장한 2채널의 음성은 Goldwave version 6.10를 이용하여 각각의 채널로 분리하였다. 채널을 분리한 후, $\mathrm{EAC} \mathrm{mic로} \mathrm{녹음한} \mathrm{음성은}$ 탐침관에 의한 영향을 배제하기 위하여 MATLAB (MathWorks, Natick, MA, USA)으로 추가 보정하였다.

포먼트 전이는 Praat (v6.0.19, University of Amsterdam, The Netherlands)을 이용하였고, Praat 파라미터는 포먼트 주파수를 최 대 $5,000 \mathrm{~Hz}$ 범위에서 5 개까지 분석할 수 있도록 설정하였다. 포먼 트 주파수는 F1, F2 또는 F3까지를 분석하는 것이 일반적이나 이 연구에서는 외이와 중이의 공명 주파수 대역을 고려하여 F3와 F4 를 모두 분석하였다. 포먼트 전이는 분명한 전이 구간을 선택한 후, 시작(첫 번째 구간, $\mathrm{T} 1$ )과 중간(두 번째 구간, $\mathrm{T} 2$ ) 및 종료 지점(세 번째 구간, T3)의 세 지점에서 각각 0.002 초 구간씩 분석하였다. 두 음성의 포먼트 전이 차이는 이원변량분석(two-way ANOVA)으로 검증하였다. 통계는 IBM SPSS Statistics version 22 (IBM, Armonk, NY, USA)를 사용하였다.

\section{연구결과}

비음/나/와 유음/라/의 전이 구간 T1, T2, T3에서 포먼트 주파수 
$\mathrm{F} 1, \mathrm{~F} 2, \mathrm{~F} 3, \mathrm{~F} 4$ 의 평균과 표준 편차는 Table 1과 같다.

/나/와 /라/의 전이 구간에서 포먼트 주파수 변화는 EAC 비음 $\mathrm{F} 1, \mathrm{~F} 2$ 와 EAC 유음 $\mathrm{F} 1, \mathrm{~F} 4$ 가 상승하였으나 통계적으로는 비음 $\mathrm{F} 1$ 만 유의한 것으로 관찰되었다 $(p=.005)$.

비음 /나/의 포먼트 전이 양상을 살펴보면, F1은 상승하는 양상 을 보였으며, $\mathrm{SF}$ 에서 중간부터 종료 지점 사이가, $\mathrm{EAC}$ 에서 시작부 터 중간 지점 사이가 더 가파르게 상승하였다. F2는 SF와 EAC 모두 완만하게 상승하는 양상이 관찰되었다. F3은 SF에서 완만하게 상 승하였고, $\mathrm{EAC}$ 에서 $\mathrm{SF}$ 와 반대로 완만하게 하강하는 양상이 관찰
되었다. F4는 SF에서 완만하게 상승하였으나 시작과 중간 지점 사 이에서 상승 정도가 크게 관찰되었고, $\mathrm{EAC}$ 에서 완만하게 하강하 는 양상이 관찰되었다.

유음 /라/의 포먼트 전이 양상의 경우, $\mathrm{F} 1$ 은 비음과 마찬가지로 크게 상승하는 양상이 관찰되었으나 EAC보다 SF에서 상승 정도 가 컸다. F2와 F3는 SF에서 상승하는 경향이, EAC에서 하강하는 경향이 관찰되었으나 F3보다 F2의 상승 또는 하강하는 정도가 컸 다. F4는 SF에서 하강하였다가 다시 상승하는 양상이 관찰되었으 나EAC에서 완만하게 상승하는 양상이 관찰되었다(Figure 2).

Table 1. Formant frequency in each transition point of /na/, /la/ in sound field and the external auditory canal

\begin{tabular}{|c|c|c|c|c|c|c|c|}
\hline & & & & & & & \\
\hline & & SF & EAC & SF & EAC & SF & EAC \\
\hline $\mathrm{F} 1$ & /na/ & $587.7 \pm 232$ & $513.2 \pm 122$ & $651.9 \pm 186$ & $601.2 \pm 104$ & $737.3 \pm 60$ & $660.2 \pm 80$ \\
\hline & /la/ & $626.9 \pm 82$ & $635.3 \pm 90$ & $647.7 \pm 70$ & $648.0 \pm 60$ & $670.1 \pm 62$ & $661.1 \pm 56$ \\
\hline F2 & /na/ & $1,319.6 \pm 92$ & $1,223.1 \pm 92$ & $1,344.4 \pm 100$ & $1,242.9 \pm 98$ & $1,369.1 \pm 89$ & $1,264.2 \pm 97$ \\
\hline & /la/ & $1,372.0 \pm 54$ & $1,316.4 \pm 117$ & $1,375.7 \pm 55$ & $1,313.7 \pm 86$ & $1,378.9 \pm 51$ & $1,310.8 \pm 65$ \\
\hline F3 & /na/ & $3,092.0 \pm 460$ & $1,785.8 \pm 157$ & $3,256.8 \pm 454$ & $1,735.8 \pm 174$ & $3,422.6 \pm 493$ & $1,688.0 \pm 185$ \\
\hline & /la/ & $2,732.1 \pm 723$ & $1,839.6 \pm 218$ & $2,755.3 \pm 718$ & $1,839.2 \pm 209$ & $2,766.7 \pm 736$ & $1,836.4 \pm 206$ \\
\hline F4 & /na/ & $4,104.2 \pm 243$ & $3,222.5 \pm 321$ & $4,184.3 \pm 249$ & $3,212.1 \pm 294$ & $4,211.3 \pm 262$ & $3,204.8 \pm 292$ \\
\hline & /la/ & $3,964.1 \pm 338$ & $3,304.8 \pm 289$ & $3,918.8 \pm 290$ & $3,315.3 \pm 270$ & $3,956.6 \pm 295$ & $3,323.9 \pm 254$ \\
\hline
\end{tabular}

Values are presented as mean \pm SD.

$\mathrm{F}=$ formant frequency; $\mathrm{T}=$ measuring point of formant transition; $\mathrm{SF}=$ sound field; $\mathrm{EAC}=$ external auditory canal.
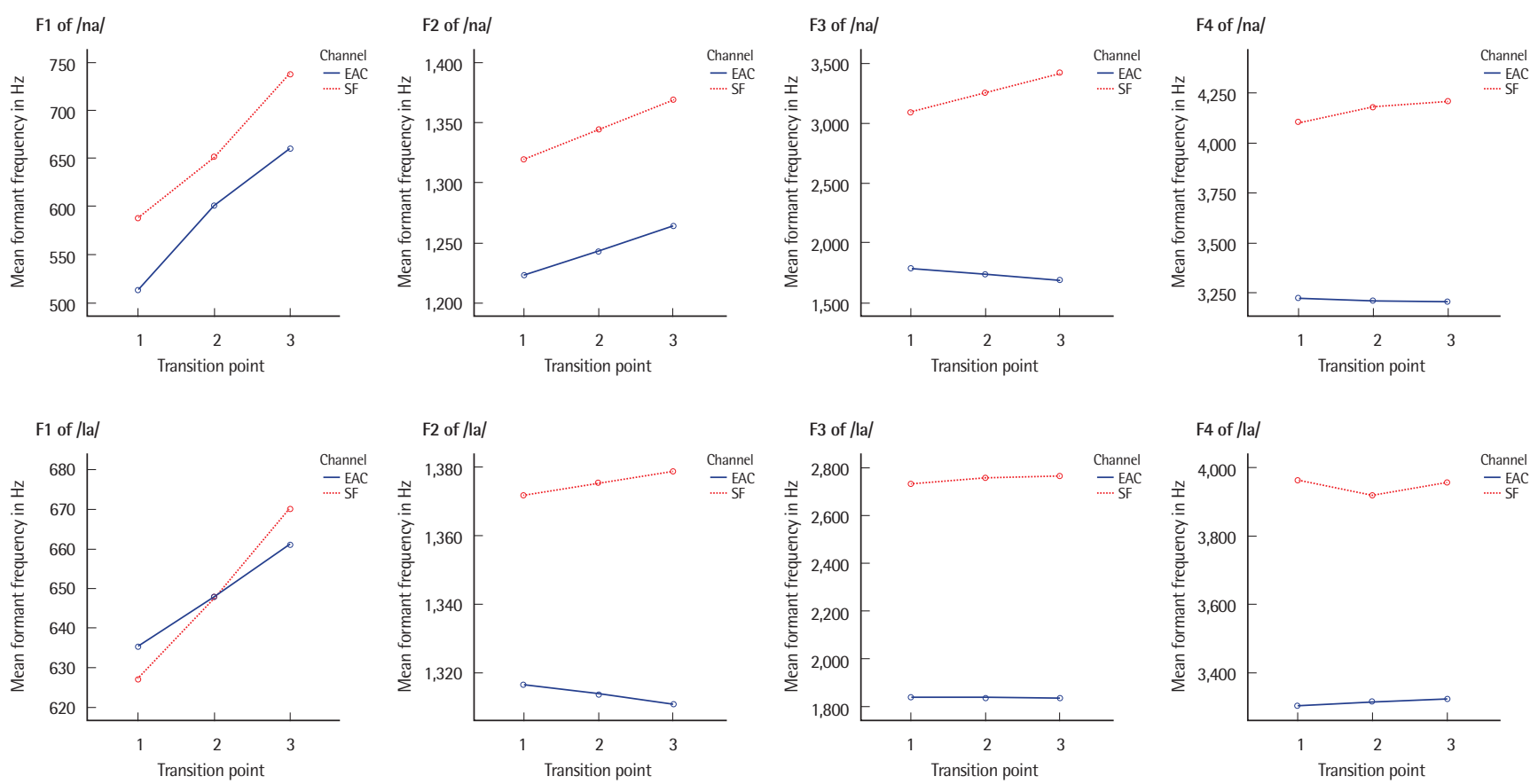

Figure 2. Pattern of formant transition of /na/ (upper), /la/ (lower) in sound field and the external ear canal (F1, F2, F3, F4 from left). $\mathrm{SF}=$ sound field; $\mathrm{EAC}=$ external ear canal. 
$\mathrm{SF}$ 와 $\mathrm{EAC}$ 에서 녹음한 두 음성의 포먼트 전이 사이에서는 비음 $/ \mathrm{na} /$ 의 경우 $\mathrm{F} 1$ ( $p=.029), \mathrm{F} 2, \mathrm{~F} 3, \mathrm{~F} 4$ ( $p=.000)$ 모두 통계적으로 유 의한 차이가 관찰되었고, 유음 $/ \mathrm{la} /$ 의 경우는 $\mathrm{F} 1$ ( $p=.995)$ 을 제외한 $\mathrm{F} 2, \mathrm{~F} 3, \mathrm{~F} 4(p=.000)$ 에서 통계적으로 유의한 차이가 관찰되었다.

\section{논의 및 결론}

포먼트 전이는 성도의 변화에 따른 포먼트 주파수의 이동을 표 현하기 때문에 자음+모음+자음(CVC)과 같이 구조를 다양하게 변화시켜 나타나는 음향학적 특성을 관찰하여 음운 현상을 설명 하는 데 유리하다. 실지로 $\mathrm{CV}$ 단음절 낱말에서 포먼트 전이는 성 장 배경에 영향을 받기도 하고(Zuo \& Mok, 2015), F0 또는 인접 자 음의 변화에 크게 영향을 받지만 말소리 지각의 일관성 유지에 기 여하며(Stachurski, Summers, \& Roberts, 2015), 전이 구간을 연장 하면 뇌에서 시간적 통합처리(temporal integration processing)가 강조되어 단순 언어장애(specific language impairment)의 파열음 인지에 도움을 줄 수도 있다(Steinschneider \& Fishman, 2011). 그 러나 CV 단음절에서는 초성 자음과 모음 사이의 전이 요인이 크더 라도 포먼트 전이가 비교적 작게 관찰된다(Stachurski et al., 2015). 따라서 외이도의 구조적 특성에 의한 포먼트 전이를 관찰하는 데 는 $\mathrm{CV}$ 음절을 안정상태에서 연장 발성하는 것이 다양한 요인으로 부터 영향을 받지 않아 유리할 수 있다.

$\mathrm{EAC}$ 음성의 음향학적 특성들은 외이의 물리적 환경과 외이 구 조에 의한 공명 등의 영향으로 달라질 수 있다(Heo \& Kang, 2017; Heo, Kang, et al., 2017). 이 연구에서 포먼트 주파수 F1부터 F4는 유음/라/의 F1의 T1과 T2를 제외하고 모두 SF보다 EAC에서 낮게 관찰되었다. 통계적으로 유의한 결과만을 살펴보면, $\mathrm{EAC}$ 의 F1, F2 는 음원으로부터 멀어져서 생긴 후설화 및 $\mathrm{EAC}$ 내부로 진입하는 과정에서 생긴 원순화에 의해, F3, F4는 공명에 의한 영향으로 각각 낮아져서 주파수가 $1,000 \mathrm{~Hz}$ 대역으로 중심화 하는 경향(Heo \& Kang, 2017; Heo, Kang, \& Ko, 2017)과 일치되는 소견이다. EAC에 서의 이러한 변화는 포먼트 주파수를 중이 공명 주파수 범위로 이 동하여 임피던스 정합에 유리한 작용을 하고(Heo \& Kang, 2017), 개인 목소리 특성을 해석하고 말소리를 이해하는 데에도 도움(Heo, Kang, et al., 2017)을 주는 것으로 보인다.

포먼트 전이를 살펴보면, $\mathrm{F} 1$ 은 CVC 단음절어에서 일차적으로 전 설과 후설 모음 집단에서 각 모음을 구별하는 데 기여하고(Yang, 2009), 전설 모음의 공명주파수에서 역동적 변화가 나타난다(Oh, 2013). 중설 저모음을 사용한 이 연구는 F1이 SF 및 EAC 모두에서 크 게 상승하는 양상으로 관찰되었다. 구체적으로 살펴보면, 비음
/나/의 경우 SF에서 점차 가파르게 상승하였고, $\mathrm{EAC}$ 에서 시작부터 가파르게 상승하였다가상승세가 둔화되는 양상으로 관찰되었다. 유 음/라/의 경우 SF에서 처음부터 가파른 상승 양상을 보인 반면 $\mathrm{EAC}$ 에서 상대적으로 완만한 상승 양상이 관찰되었다. 두 유성 자음의 관 계를 주파수만으로 살펴보면 비음은 전이에도 불구하고 $\mathrm{EAC}$ 가 낮 았으나 유음은 전이 후 $\mathrm{EAC}$ 가 $\mathrm{SF}$ 보다 낮아지는 역전 현상이 발생하 여, 전설에서 관찰할수 있는 역동적 변화(Oh, 2013)가 관찰되었다.

F2 포먼트 전이는 모음 인지와 관련한 연구들에서 주로 관찰한다. $\mathrm{CVC}$ 단음절어에서 조음 위치에 따라 전설 모음 집단이 하강하고 후설 모음 집단의 경우 자음 / $\mathrm{d} /$ 와 공동 조음에 영향이 크다(Yang, 2009). 그러나 말더듬이 있는 경우 주파수 범위가 넓으며, 전이 양상 이 정상과 비슷하지만 시간이 길고 경사가 큰 경향을 보인다(Dehqan, Yadegari, Blomgren, \& Scherer, 2016). 의사소통 과정에서도 정상 청력자가 수화와 구어처럼 두 개의 도구를 동시에 사용하더라 도 영향을 받지 않는다(Baillargeon, McLeod, Metz, Schiavetti, \& Whitehead, 2002). 이 연구에서 F2 포먼트 전이는 비음의 경우 SF 와 마찬가지로 상승하는 양상을 보였으나 유음의 경우 SF와 달리 하강하는 양상으로 관찰되었다.

음향학적 연구에서 포먼트는 F1, F2에 집중하는 경향이어서 F3 이후에 대한 정보가 많지 않다. CVC 단음절 낱말에서도 F3 포먼트 전이는 기여하는 바가 관찰되지 않았다(Yang, 2009). 이 연구에서 $\mathrm{F} 3$ 포먼트 전이는 비음의 경우 SF에서 높아지고, $\mathrm{EAC}$ 에서 낮아지 는 경향을 보였으나 유음의 경우 변화가 관찰되지 않았다. F4 포먼 트 전이는 비음의 경우 $\mathrm{SF}$ 에서 상승하였다가 상승세가 둔화되는 양상으로 관찰되었으나 $\mathrm{EAC}$ 에서 일정하게 유지되는 양상으로 관 찰되었다. 유음의 경우 SF에서 낮아졌다가 다시 높아졌고, $\mathrm{EAC}$ 에 서 아주 완만하게 높아지는 양상이 관찰되었다.

$\mathrm{SF}$ 에서 비음의 포먼트 전이가 높아진 것은 비음의 공명주파수가 모음에 비하여 낮은(Lee, Jang, \& Chung, 2005) 것과 관련될 것으 로 추정되며, 유음에서도 F4 포먼트 전이가 낮아졌다가 다시 높아 지는 것을 제외하고 대체로 높아진 것은 F2와 F3가 근접하면서 모 음/아/에 의한 영향(Jo, 2014)과 유음의 낮은 공명주파수 영향이 함 께 작용하였을 것으로 추정된다.

이상을 요약하면, 외이도에서 녹음한 비음 /나/와 유음 /라/의 포 먼트 전이는 그 양상이 음장에서의 변화와 다르게 관찰되었다. 외 이도 비음의 포먼트 전이는 F1, F2가 높아졌고 F3가 낮아졌으며 F4 가 유지되는 양상이었다. 외이도 유음의 포먼트 전이는 F1과 F4이 높아졌으나 F4는 수평에 가깝게 완만하였고, F2가 낮아졌으며, F3 는 변하지 않는 양상으로 관찰되었다. 이러한 변화는 음장에서 전 반적으로 높아진 것과 비교하면 외이도의 비음 F3, F4에서, 외이도 
유음 F2, F3, F4에서 각각 그 간격이 벌어진 것으로, 이들 포먼트 주 파수 간격의 변화는 말소리의 변별 자질을 향상시키는 데 도움을 줄 것으로 판단한다.

포먼트 전이는 시간적 통합 처리를 강조하여 파열음 인식에 도움 을 줄 수 있는데(Coez et al., 2010; Steinschneider \& Fishman, 2011), 이 연구에서 나타난 결과는 보청기 사용자의 자음 탈락이나 대치 원인을 공명 손실에 의한 청각적 단서 부족은 물론 또 다른 시각에 서 탐색할 필요가 있다는 것을 암시하는 단서이다. 이러한 문제는 전기생리학적 연구와 융합하여(Carpenter \& Shahin, 2013) 포먼트 전이가 청각처리에 미치는 영향이나 환기구 공명 변화( $\mathrm{Kim} \& \mathrm{HeO}$, 2016)이 포먼트 주파수에 미치는 영향 등과 같은 후속연구가 필요 할 것으로 보이며, 이러한 연구들이 조음 음운 오류나 올바른 음향 정보 제공에도 나타나는 말소리 장애(Won \& Ha, 2015)의 원인 분 석에도 도움이 될 것으로 기대된다.

\section{ACKNOWLEDGEMENT}

The authors would like to express their appreciation to Dr. GiRyon Kim, Mr. KwangNyeon Kim at PhysioLab Co., Ltd. and Ms. MinHee Lee at HaNa ENT Hospital, for their technical assistance.

\section{REFERENCES}

Baillargeon, M., McLeod, A., Metz, D. E., Schiavetti, N., \& Whitehead, R. L. (2002). Preservation of second formant transitions during simultaneous communication: a locus equation perspective. Journal of Communication Disorders, 35, 51-62.

Carpenter, A. L., \& Shahin, A. J. (2013). Development of the N1-P2 auditory evoked response to amplitude rise time and rate of formant transition of speech sounds. Neuroscience Letters, 544, 56-61.

Choi, S. H., Nam, D. H., Lim, J. Y., Lim, S. E., \& Choi, H. S. (2007). Phonatory Characteristics of vowels and resonant consonants using the electroglottography. The Journal of the Korean Society of Logopedics and Phoniatrics, $15,133-140$.

Coez, A., Belin, P., Bizaguet, E., Ferrary, E., Zilbovicius, M., \& Samson, Y. (2010). Hearing loss severity: impaired processing of formant transition duration. Neuropsychologia, 48, 3057-3061.

Dehqan, A., Yadegari, F., Blomgren, M., \& Scherer, R. C. (2016). Formant transitions in the fluent speech of Farsi-speaking people who stutter. Journal of Fluency Disorders, 48, 1-15.
Heo, S. D., Choi, A. H., \& Kang, M. G. (2006). Rehabilitative audiology cochlear implant, hearing aids, binaural hearing. Seoul: SigmaPress.

Heo, S. D. (2012). Pure external audiology canal resonance. Journal of Speech \& Hearing Disorders, 21, 465-473.

Heo, S. D., \& Kang, H. (2017). Formant frequency changes of female voice /a/, /i/, /u/ in real ear. Phonetics and Speech Sciences, 9, 49-53.

Heo, S. D., Kang, H. R., \& Ko, D. H. (2017). Influence of real ear resonance on male voice formant frequency. Communication Sciences \& Disorders, $22,608-614$.

Heo, S. D., Lee, J. H., Jeon, S. M., \& Kim, I. A. (2010). Resonance in the concha cavity associated with the size of the pinna. Korean Journal of Communication Disorders, 15, 120-126.

Heo, S. D., Park, C. H., \& Song, B. S. (2017). Comparison of smart phone application based hearing screening and hearing handicap Inventory. Journal of Rehabilitation Welfare Engineering \& Assistive Technology, 10, 73-79.

Jo, N. M. (2014). Research on the allophone of the word-initial liquid in Korean: on the relationship between the localization consciousness of Korean loanword and the phonetic realization of liquids. The Journal of Linguistic Science, 70, 433-460.

Johnson, K. (2003). Acoustic \& auditory phonetics (2th ed., H. S. Park, Trans.). Seoul: Hanbitmunhwa.

Kim, M., \& Heo, S. (2016). Effects of vent diameter on real ear acoustics. Audiology and Speech Research, 12, 204-208.

Lee, J. H., Jang, H. S., \& Chung, H. J. (2005). A study on frequency characteristics of Korean phonemes. Audiology and Speech Research, 1, 59-66.

Oh, E. (2013). Formant transition shapes of Korean front vowels. Phonetics and Speech Sciences, 5, 195-200.

Stachurski, M., Summers, R. J., \& Roberts, B. (2015). The verbal transformation effect and the perceptual organization of speech: influence of formant transitions and F0-contour continuity. Hearing Research, 323, 22-31.

Steinschneider, M., \& Fishman, Y. I. (2011). Enhanced physiologic discriminability of stop consonants with prolonged formant transitions in awake monkeys based on the tonotopic organization of primary auditory cortex. Hearing Research, 271, 103-114.

Won, M., \& Ha, S. (2015). Final stop consonant perception in children with speech sound disorders. Communication Sciences \& Disorders, 20, 145-156. Yang, B. G. (2009). Formant trajectories of English vowels produced by American males. Phonetics and Speech Sciences, 1, 65-72.

Zuo, D., \& Mok, P. P. K. (2015). Formant dynamics of bilingual identical twins. Journal of Phonetics, 52, 1-12. 


\section{국문초록}

\section{외이도에서 비음과 유음 포먼트 전이}

허승덕'

${ }^{1}$ 대구대학교 재활과학대학 언어치료학과, ${ }^{2}$ 대구대학교 일반대학원 재활과학과

배경 및 목적: 말소리는 외이를 통과해야 듣고 이해할 수 있는데, 외이는 공기를 매질로 소리를 전달한다. 따라서 말소리는 외이의 구조 나 매질의 물리적 특성에 따라 음향특성이 달라질 수 있다. 이 연구는 외이의 외이 영향을 받은 비음과 유음의 포먼트 전이를 살펴보는 데 목적이 있다. 방법: 연구에는 청각기관 및 조음기관에 이상이 없는 건강한 남녀 16 명이 참여하였다. 참여자 중 1 명은 화자로, 나머지 15 명은 청자로 역할을 나누었다. 음성은 비음 /ㄴ/과 유음/리을 모음 / / / 에 연결한 단음절 낱말을 이용하였다. 녹음은 이개 상부인 sound field (SF)와 the external auditory canal (EAC) 내부에 각각 장착한 고성능 콘덴서 마이크를 이용하였다. 녹음한 음성은 MAT$\mathrm{LAB}$ 으로 보정한 후 Praat으로 포먼트 전이를 분석하였다. 두 음성의 차이는 이원변량분석(two-way ANOVA)으로 검증하였다. 결과: $\mathrm{SF}$ 에서 포먼트 전이는 비음의 경우 모두 높아졌고, 유음도 F4가 낮아졌다가 다시 높아지는 것을 제외하고 대체로 높아졌다. $\mathrm{EAC}$ 에서 포먼트 전이는 비음의 경우 F1, F2만 높아졌고 F3가 낮아졌으며 F4가 유지되는 양상이었다. 유음의 경우 F1과 F4이 높아졌으나 F4는 수 평에 가깝게 완만하였고, $\mathrm{F} 2$ 가 낮아졌으며, F3는 변하지 않는 양상으로 관찰되었다. 논의 및 결론: 외이도 음성의 포먼트 전이는 비음 $\mathrm{F} 3, \mathrm{~F} 4$, 유음 F2, F3, F4의 포먼트 간격을 넓게하여 말소리의 변별 자질 향상에 기여한다.

핵심어: 포먼트, 포먼트 전이, 비음, 유음, 외이도, 실이

본 연구는 2017 대구대학교 학술연구비 지원을 받아 수행하였음.

\section{참고문헌}

김민성, 허승덕(2016). 환기구 직경이 실이 음향에 미치는 영향. 한국청각언어재활학회지, 12, 204-208.

양병곤(2009). 미국인 남성이 발음한 영어 모음의 포먼트 궤적. 말소리와음성과학, 1, 65-72.

오은진(2013). 한국어 전설 모음의 포먼트 전이 형태. 말소리와음성과학, 5, 195-200.

원민주, 하승희(2015). 말소리장애 아동과 일반 아동의 종성파열음지각력 연구. 언어청각장애연구, 20, 145-156.

이주현, 장현숙, 정한진(2005). 한국어 음소와주파수 특성에 관한 연구. 청능재활, 1, 59-66.

조남민(2014). 한국어 어두 유음의 변이음에 관한 연구. 언어과학연구, 70, 433-460.

최성희, 남도현, 임재열, 임성은, 최홍식(2004). 전기성문파형검사를 이용한 모음과 공명 자음의 발성특성. 대한후두음성언어의학회, 15, 133-140.

허승덕(2012). 순수 외이도 공명. 언어치료연구, 21, 465-473.

허승덕, 강희라(2017). 실이에서 여자 음성///,///,/T/의 포먼트 주파수 변화. 말소리와음성과학, 9, 49-53.

허승덕, 강희라, 고도흥(2017). 외이 공명이 남자 음성 포먼트 주파수에 미치는 영향. 언어청각장애연구, 22, 608-614.

허승덕, 박찬호, 송병섭(2017). 스마트 폰 애플리케이션 기반 청각선별과 설문 청각선별의 비교. 재활복지공학회논문지, 11, 73-79.

허승덕, 이제현, 전성민, 김인하(2010). 이개 크기에 따른 이개강 공명. 언어청각장애연구, 15, 120-126.

허승덕, 최아현, 강명구(2006). 재활청각학. 인공와우, 보청기, 양이청취. 서울: 시그마프레스.

Keith Johnson (2003). 음향 및 청취음성학의 이해(제2판, 박한상 역). 서울: 한빛문화. 